Dos, paseos por los bosques narrativos (un lugar para la ficción)

\title{
El narrador no confiable en Robert Walser y Carlo Emilio Gadda: una lectura comparada Fabricio Welschen
}

\section{Welschen, Fabricio}

Fabricio Welschen Sobre el autor Universidad Nacional del Litoral, Argentina

\section{El hilo de la fábula}

Universidad Nacional del Litoral, Argentina

ISSN: 1667-7900

ISSN-e: 2362-5651

Periodicidad: Anual

vol. 19, núm. 21, 2021

revistaelhilodelafabula@fhuc.unl.edu.ar

Recepción: 18 Febrero 2021

Aprobación: 19 Marzo 2021

DOI: https://doi.org/10.14409/hf.v0i21.10564
Resumen: En este artículo exploraremos algunos puntos en común entre los escritores Robert Walser y Carlo Emilio Gadda; específicamente, el empleo del narrador no confiable en las novelas Der Räuber (1925) y La cognizione del dolore (1963/1970). De este modo, argumentaremos cómo la aparición del narrador no confiable está en línea con el programa narrativo vanguardista y experimental de estos dos autores, cuya contribución fue decisiva para la literatura del siglo XX.

Palabras clave: Robert Walser, Carlo Emilio Gadda, Narrador no confiable.

\begin{abstract}
In this article we will explore some points in common between the writers Robert Walser and Carlo Emilio Gadda; specifically, the use of the unreliable narrator in the novels Der Räuber (1925) and La cognizione del dolore (1963/1970). In this way, we will argue how the appearance of the unreliable narrator is in line with the avant-garde and experimental narrative program of these two authors whose contribution was decisive for 20th century literature.
\end{abstract}

Keywords: Robert Walser, Carlo Emilio Gadda, Unreliable narrator.

Las figuras del suizo de lengua alemana Robert Walser y del italiano Carlo Emilio Gadda tienen mucho más en común de lo que, en un principio, parecerían indicar las coordenadas espaciales.

Un primer punto de contacto: a pesar de estar, en cierto modo, a la sombra de grandes autores del siglo XX (la sombra de Franz Kafka y Thomas Mann en la literatura en lengua alemana; la sombra de Cesare Pavese en la literatura italiana) los aportes de Walser y Gadda fueron imprescindibles para el enriquecimiento de la literatura a la que pertenecían: el suizo fue una influencia decisiva en la narrativa de Kafka, mientras que el lombardo llevó a cabo un programa narrativo que permitió renovar la literatura italiana de posguerra, caracterizada por un predominio de las fórmulas del neorrealismo.

Un segundo punto en común: el carácter innovador, y por ende extraño, de sus propuestas narrativas. En efecto, novelas como Jacob von Gunten (1909) y El zafarrancho aquel de via Merulana (1957) se sustentan en una narración que desbarata las formas típicas a las que hasta entonces adscribían las obras en lengua 
alemana y lengua italiana; ${ }^{1}$ de ahí el extrañamiento que provocan esas novelas. Por eso mismo, se trata de narraciones que suponen un punto de inflexión con sus antecedentes inmediatamente anteriores (el realismo decimonónico y el neorrealismo, respectivamente) aunque no, como podría pensarse a priori, por el hecho de impugnar el realismo sino, más bien, por la pretensión de ampliar esa misma noción de realismo. Esta impronta constituye un aporte decisivo en sus respectivas literaturas.

Para indagar justamente en el carácter innovador de estos dos autores nos detendremos a analizar la presencia de la figura del narrador no confiable en sus novelas Der Räuber (1925) y La cognizione del dolore (1963/1970).

La problemática del narrador no confiable se ha revelado en las últimas décadas como uno de los temas más abordados en trabajos académicos sobre literatura, mayoritariamente en aquellos pertenecientes a universidades anglófonas. Rabinowitz señala que un narrador no confiable es aquel que «miente, oculta información, hace juicios errados respecto a la audiencia narrativa» (Rabinowitz, 2015: 210).

Podríamos sumar, también, la definición del término que Baldick realiza en The Concise Oxford Dictionary of Literary Terms:

\footnotetext{
Un narrador cuyo relato de los hechos parece ser defectuoso, engañosamente sesgado o bien distorsionado, de modo que se aparta de la comprensión 'verdadera' de los hechos compartidos entre el lector y el supuesto autor (...) El término no implica necesariamente que este tipo de narrador sea moralmente indigno de confianza o un mentiroso habitual (aunque esto puede ser así en algunos casos) ya que la categoría incluye también a narradores inofensivamente ingenuos, 'falibles' o mal informados ${ }^{2}$ (Baldick, 2008:347).
}

Algunos ejemplos emblemáticos de esta figura literaria se pueden encontrar en novelas como Otra vuelta de tuerca (1898) de Henry James (cuyo final ambiguo deja al criterio del lector lo que sucedió: ‘realmente había fantasmas o fue todo producto de la imaginación de la histérica institutriz narradora?) o El asesinato de Roger Ackroyd (1926) de Agatha Christie (que cuenta con un final sorpresivo en el que se revela que el asesino es el propio narrador, personaje del que difícilmente se podría llegar a sospechar debido a la confianza que, por tradición, el lector de las narraciones policiales deposita en él).

Pero, tal como sostiene Baldick, hay distintas modalidades del narrador no confiable y no siempre es indigno de confianza debido a que se trata de un asesino que intenta encubrir su crimen o de un sujeto que cuenta con una visión distorsionada de la realidad. En ocasiones, el narrador no confiable no tiene una motivación determinada y su no confiabilidad se encuentra más bien en consonancia con el tipo de narración en el que aparece. Esto no sería de extrañar si tenemos en cuenta que la figura del narrador no confiable supone un cuestionamiento al estatuto de una de las nociones fundamentales de la narrativa como lo es la del narrador. Con lo cual, es factible considerar que este tipo de figura puede aparecer en textos que, por su impronta vanguardista, reconfiguran la categoría de narrador.

En los casos en los que nos centraremos, no puede dejar de observarse una simbiosis entre el empleo que Walser y Gadda hacen de la figura del narrador no confiable y sus respectivos programas narrativos. Es decir que la presencia del narrador no confiable en sus novelas lejos se encuentra de ser un hecho 
anecdótico, teniendo en rigor un alcance significativo en el que se demuestra el carácter innovador de estos dos escritores. Así, la presencia del narrador no confiable en novelas puntuales de Robert Walser y Carlo Emilio Gadda es solo una de las muestras, entre otras, del carácter innovador de la narrativa de estos autores en relación a las convenciones de la novela.

Por lo demás, es evidente que el análisis de la figura del narrador no confiable en novelas pertenecientes a sistemas literarios distintos a los fines de poner sobre el tapete los puntos en común entre Walser y Gadda se encuentra impulsado por el convencimiento, propio de la Literatura Comparada, de que mediante la focalización en los puntos en común de dos autores diferentes se podrá apreciar la dimensión de cada uno y, más específicamente, sus aportes a la literatura universal. La propia dinámica de los programas narrativos de estos dos autores demanda, por cierto, un tipo de lectura comparatista puesto que constituyen casos excepcionales dentro de sus respectivos sistemas literarios. $\mathrm{Y}$, en este sentido, la Literatura Comparada es el marco adecuado desde el cual realizar esta lectura, ya que «si hay algo que define al comparatismo es el afán, el deseo y la voluntad de superar lo cerrado, lo inmóvil, lo individual» (Crolla, 2005: 10).

\section{Divagaciones y promesas incumplidas del narrador en El bandido de Robert Walser}

El bandido es una novela fechada en 1925 , antes del ostracismo voluntario al que se sometió Walser internándose en sanatorios para enfermos mentales, donde permanecería durante treinta años hasta su trágica muerte en la gélida navidad de 1956. La novela fue publicada póstumamente y por ende no escapa a la condición de borrador. No obstante, a pesar del carácter en cierto modo inacabado (en el sentido de no definitivo) de El bandido, se puede apreciar en ella algunos de los elementos recurrentes de la narrativa de Walser, que se encuentran presentes en sus tres novelas principales: Los hermanos Tanner (1907), El ayudante (1908) y Jakob von Gunten. Por ejemplo, la relativización de los límites entre la primera y la tercera persona narrativa que tiene lugar en el célebre episodio del hallazgo del cadáver congelado en Los hermanos Tanner ${ }^{3}$ aparece acentuada en El bandido, con un narrador de la historia que por momentos parece confundirse o mimetizarse con el protagonista, un empedernido seductor de mujeres:

Ser tan olvidadizo es realmente imperdonable. Cierta vez, en un pequeño y pálido bosque de noviembre, y después de detenerse en una imprenta y de haber charlado una horita con el propietario de la misma, el bandido se cruzó con la mujer pintada por Henri Rousseau, totalmente vestida de marrón. Se quedó atónito. Le vino a la cabeza la idea de que, tiempo atrás, con motivo de un viaje en tren y en medio de la noche, le había dicho a una mujer que viajaba con él las siguientes - si así puede decirse - palabras exprés: «Voy a Milán». Del mismo modo, con la rapidez de un rayo, pensó en las chocolatinas que uno compra en las tiendas de especias. Hacen las delicias de los niños, y también las del bandido, que de vez en cuando comía algunas, como si la debilidad por las chocolatinas fuera una de las obligaciones de todo buen bandido. «No mientas», dijo la dama de marrón, abriendo su encantadora boca. Interesante, ¿verdad?, esta boca tan encantadora, y prosiguió: «Pretendes siempre hacer creer a todos los que te rodean y quisieran hacer de ti un hombre de provecho que te falta aquello que es importante para la vida y sus placeres. Pero ¿te falta ese algo tan esencial? No. Lo tienes de sobra. Es sólo que no te importa, que lo consideras un 
lastre. Durante toda tu vida has ignorado el bien que poseías». «Yo no tengo ningún bien al que no le hubiera sacado partido», repliqué. (Walser, 2010: 17-18)

Probablemente ese carácter olvidadizo del cual el narrador advierte al lector al principio de la novela contribuya a la flexibilización de los límites entre narrador y personaje; como si por momentos el narrador olvidara su pretendido rol de narrador omnisciente (pasando, así, indiscriminadamente de un «le había dicho» a un «repliqué»).

Pero al margen de los motivos, lo cierto es que esta característica del narrador de El bandido supone una reconfiguración de una categoría tradicional de la literatura (específicamente en la narrativa) como lo es la de narrador, puesto que la mencionada confusión o mimetización con el personaje evidencia que el narrador se encuentra condicionado por la perspectiva de aquel, lo cual lo aleja de uno de los preceptos esenciales del narrador omnisciente como lo es la objetividad (objetividad que implica una distancia con sus consiguientes límites bien definidos).

No se trata por cierto del único rasgo distintivo del narrador de Walser. Su tendencia a las divagaciones, que se constituye en una constante a lo largo de toda la narración de El bandido, lo emparenta con el narrador de la novela inglesa El buen soldado (1915) de Ford Madox Ford, emblemática justamente por el novedoso empleo del narrador en primera persona. ${ }^{4} \mathrm{El}$ mismo narrador tiene conciencia de su tendencia a irse por las ramas. Es por eso que, después de que en el párrafo anterior se pusiera a discurrir sobre un tema absolutamente menor e intrascendente en relación a la historia, el narrador admite: «Como en el párrafo que acabo de armar me he engrandecido, y eso es algo que podría disuadir a algunos lectores de continuar leyendo, ahora me calmaré, templaré mis ánimos y me haré más pequeño que un dedal» (Walser, 2010: 92). Como se puede ver, no solo se trata de un narrador que tiene conciencia de su narración dispersa (y, por ende, poco concreta y precisa) sino que además es consciente de que se encuentra inmerso en una novela; es decir, la explicitación del artificio, una dimensión metaficcional que le otorga mayor complejidad al narrador que presenta Walser en El bandido.

Pero si hay un aspecto en el que decididamente se dirime el carácter «no confiable» de este narrador es en los recurrentes incumplimientos de las promesas que éste le hace al lector. Promesas de que se narrarán determinados episodios (ya sean triviales o decididamente trascendentes para que el lector pueda comprender determinadas cuestiones de la historia).

En una ocasión le llevó [el Bandido] una maleta pequeña a una mujer hasta el umbral del lugar al que le había conducido la caminata, servicio por el cual recibió un franco de su mano enguantada (...) Cada ocho días tomaba una ducha, bajo el chorro de la cual jugaba a ser un negrito que la lluvia hacía bailar. De esa ducha hablaremos tal vez más abajo. Pero de momento me permito añadir la razón por la cual no puedo entrar en el café de damas (...) un buen día, se presentó una de las más bellas jóvenes que he visto en mi vida, una brasileña con la cual, ya que se había sentado a mi lado, entablé una conversación. Me dijo que tenía en su haber a quinientos negros. (Walser, 2010: 40-41)

Desde luego que en este pasaje, además de la recurrente confusión entre narrador y personaje, tiene lugar la anticipación de una anécdota (que en este caso, el de la ducha, podemos suponer trivial) de la que el narrador 
nunca terminará rindiendo cuenta. La novela continúa bajo este registro de divagaciones, anticipaciones de episodios nunca narrados e incertidumbres. Por lo demás, el mismo narrador no deja de reconocerse a sí mismo como no confiable: «Bien que mal, pues, conservo la batuta en esta historia de bandidos. Creo en mí. El bandido no acaba de confiar en mi persona, pero yo no doy demasiada importancia a que la gente crea en mí» (Walser, 2010: 116).

Esta violación del pacto de lectura establecido entre el lector y el narrador termina por configurar un tipo de narrador no confiable, aunque no se encuadre dentro de la tipología esbozada por Baldick (tipología en la que aparece desde un narrador mentiroso hasta uno mal informado o ingenuo). En el caso del narrador no confiable de El bandido se trata de uno que responde más bien a la dinámica propia del texto en el que se encuentra inmerso. En otras palabras: teniendo en cuenta que el foco de la novela de Walser se encuentra más sobre el discurso mismo de la narración que sobre la trama en sí, es factible determinar que la falta de fiabilidad de su narrador no responda a «motivos personales» (como sí los podrían tener los narradores de las anteriormente mencionadas novelas de Henry James y Agatha Christie) sino al hecho de que ese tipo de narrador no confiable se ajusta a la impronta experimental de El bandido.

En este sentido, cabe preguntarse cuánta incidencia ha tenido sobre esta configuración del narrador no confiable la condición de borrador de El bandido. Sin duda que el carácter experimental que adquiere la narración de la novela debe mucho a esta condición textual. Aun así, tal como se ha señalado anteriormente, a pesar de no haber estado en los planes de Walser publicarla, lejos se encuentra esta de constituir una anomalía dentro de la producción literaria del escritor suizo, puesto que en su novedoso despliegue narrativo a partir de la categoría del narrador se acentúan y confirman tendencias ya presentes en las novelas principales del autor. Teniendo en cuenta esto, El bandido sea probablemente la manifestación más radical y, por ende, moderna de un autor que desde principios del siglo XX se perfilaba como decididamente innovador.

\section{El misterio sin resolución en El aprendizaje del dolor de Carlo Emilio Gadda}

Si bien El aprendizaje del dolor de Carlo Emilio Gadda no se trata de un borrador $\mathrm{y}$, de hecho, constituye una de las dos novelas principales del autor lombardo, no por eso deja de compartir con El bandido de Walser cierto carácter de inacabado. ${ }^{5}$ $Y$ esta es una característica que se debe al tipo de narrador que aparece en la novela.

En este caso, se trata de un narrador netamente en tercera persona; con lo cual nos encontraríamos ante una modalidad de narrador no confiable que se diferencia de los modelos típicos. De este modo, el narrador de la novela de Gadda va más allá, incluso, que el de la novela de Walser, porque al menos en este último el narrador en tercera persona se confundía con una primera. Y sin embargo, a pesar de tratarse rigurosamente de un narrador en tercera persona, el de la novela de Gadda no deja de ser no confiable.

En el caso en cuestión el carácter no confiable del narrador reside en una manifiesta desarticulación del horizonte de expectativas básico con el que cuenta cada lector; a saber: que el narrador le termine de contar la historia que ha empezado. El hecho es que la atmósfera opresiva en la que transcurre la trama de 
El aprendizaje del dolor llega a su clímax con el descubrimiento de la muerte de la madre del protagonista, el neurótico Gonzalo Pirobutirro, y acto seguido, en lo que implica un abrupto final de facto en la novela, se interrumpe la narración. No se trata de algo menor si se tiene en cuenta que en los capítulos anteriores el autor insinúa algunas posibilidades que podrían explicar la posterior muerte de la mujer (desde la hipótesis de que se trate de la obra de los ladrones que asolan al Maradagal - país ficticio en el transcurre la novela - hasta la de que el asesino sea el propio protagonista). El hecho de que se interrumpa la narración en medio de un esperable esclarecimiento del misterio no hace más que recalcar la constatación de que en esta novela nos enfrentamos a un narrador no confiable, por más que este no tenga motivo alguno para no esclarecerlo. En su nota al pie a este abrupto final de facto, María Nieves Muñiz afirma que «consustancial a Gadda es la tendencia a la obra inacabada, correlativa a su antinarratividad divagatoria y a su sintaxis 'elicoidal' o de 'sacacorchos'» (Muñiz, 1989:287). Si bien «antinarratividad» tal vez no sea el término más adecuado para referirse a la escritura de Gadda (Quer pasticciaccio brutto de via Merulana no es La Jalousie de Robbe-Grillet), lo cierto es que rinde cuenta de su impronta experimental y vanguardista. Y no hay duda de que la de Gadda es una literatura experimental y de vanguardia. Así queda demostrado en El zafarrancho aquel de via Merulana, con su recreación de los dialectos; novela en la que, por lo demás, también hay un crimen que queda sin resolver, pero cuyo final no resulta, ni mucho menos, tan abrupto y arbitrario. Y así se demuestra, también, con la interrupción de la narración en El aprendizaje del dolor, puesto que la configuración del narrador no confiable de esta novela responde al programa narrativo vanguardista de Gadda.

No obstante, este narrador en tercera persona no confiable no solo se revela como tal en el final de la novela con la interrupción de la narración. Tal como observa Muñiz, en los capítulos anteriores el narrador, al igual que el de $E l$ bandido de Walser, también se ha caracterizado por su tendencia a la dispersión en el discurrir narrativo. Así queda explicitado en una de las secciones del capítulo I de El aprendizaje del dolor, en la que el narrador se deja llevar por un discurrir en el que describe pormenorizadamente una villa hasta que de repente parece tomar conciencia de su divagación:

¡De villas y villas!, de villitas ocho habitaciones dobles servicios; de principescas villas cuarenta estancias amplia terraza a los lagos vista panorámica de Serruchón huerto, vergel, garaje, portería, tenis, agua potable, pozo negro de más de setecientos hectólitros -, orientadas a mediodía, a poniente, a levante, a levante-mediodía, a mediodía-poniente, protegidas por olmos o por antiguas umbrosidades de hayas contra la tramontana y el pampero, pero no contra los monzones de las hipotecas que también soplan a placer sobre el anfiteatro morrénico del Serruchón y a lo largo de las choperas de El Prado; ¡de villas y villucas!, de villazas colmadas, de villitas aisladas, de villas dobles, de casas con ribetes de villa, de villas rústicas, de rusticidades envilladas, los arquitectos pastrufacianos habían alhajado poco a poco, y más o menos todos, las hermosísimas y plácidas laderas de las colinas preandinas que, ni que decir tiene, "bajan en dulce pendiente" hasta los plácidos remansos de sus lagos.

(...)

Pero basta ya de enumeración de las excogitaciones funcionales (Gadda, 1989:84-87).

A pesar de adoptar la tercera persona, el narrador no confiable de Gadda se toma licencias (como las digresiones arbitrarias) propias de una primera persona. 
No solo eso: también es un narrador consciente del proceso de escritura hasta el punto de explicitarlo. Una muestra más de que a pesar de tratarse de una tercera persona narrativa, el narrador de la novela de Gadda puede ser considerado como no confiable, a la manera de los modelos tradicionales, no solo porque se trata de un narrador que se toma atribuciones propias de la subjetividad inherente a la primera persona narrativa sino también, fundamentalmente, por desbaratar el pacto de lectura propio del vínculo entre narrador y lector.

\section{A modo de conclusión}

La perspectiva comparatista nos ha permitido realizar una lectura de dos autores pertenecientes a sistemas literarios diferentes en la que se evidencia la configuración de un tipo de narrador no confiable diferente a casos más tradicionales (es decir, aquellos que son no confiables por mentirosos, trastornados o despistados). ${ }^{6}$

Esta lectura en clave comparada de Robert Walser y Carlo Emilio Gadda, en la que se explicitaron las semejanzas en el empleo de esta figura literaria, evidencia cómo la configuración de este tipo de narrador no confiable se diferencia notablemente de los modelos tradicionales puesto que, en estos dos casos, responde a cuestiones netamente programáticas, narrativas. Se trata, en suma, de un narrador cuya dudosa o relativa fiabilidad se encuentra en consonancia con la impronta experimental de las novelas en las que aparecen.

A su vez, la presencia de esta configuración del narrador no confiable en las novelas de Walser y Gadda permite dimensionar el carácter vanguardista de estos dos autores y, por lo tanto, la incidencia de sus obras en sus respectivos sistemas literarios.

En este sentido, el narrador no confiable es tan solo una excusa (aunque, desde luego, para nada menor e insignificante) para la focalización en las afinidades de dos autores trascendentes que supusieron un punto de inflexión en la literatura del siglo XX.

\section{Referencias}

BALDICK, Chris (2008). The Concise Oxford Dictionary of Literary Terms. Oxford University Press.

CROLLA, Adriana (2005). Las palabras andantes. Hilo de la fábula, 1(1), 9-11.

GADDA, Carlo Emilio (1989). El aprendizaje del dolor [traducción de Juan Petit, Juan Ramón Malovier y María Nieves Muñiz]. Catedra.

MUÑIZ, María Nieves (1989). Anotación al cap. IX en GADDA, C. E. El aprendizaje del dolor. Catedra.

RABINOWITZ, Peter (2015). La verdad en la ficción: Una reevaluación de las audiencias. Sincronía, 68, 194-220. http://www.redalyc.org/articulo.oa?id=5138 51506016

WALSER, Robert (2010). El bandido [traducción de Juan de Sola Llovet]. Siruela.

WALSER, Robert (2008). Los hermanos Tanner [traducción de Juan José del Solar]. Siruela. 


\title{
Notas
}

1 Tener en cuenta que la primera novela importante de Thomas Mann, Los Buddenbrook (1901), es solo ocho años anterior a Jacob von Gunten y las diferencias entre una y otra resultan notables: mientras que la novela de Mann sigue adscribiendo a la estética decimonónica, la de Walser presenta un discurrir narrativo que se escapa del modelo tradicional. En otras palabras: la composición de Los Buddenbrook remite a la de novelas del siglo XIX como Madame Bovary (1856) de Gustave Flaubert o Ana Karenina (1877) de León Tolstoi, en tanto que la composición de Jacob von Gunten prefigura la de El proceso (1925) de Franz Kafka.

En el caso de la literatura italiana, el predominio (en consonancia con el plano cinematográfico) del neorrealismo italiano encontraría su nota disonante en la obra de Carlo Emilio Gadda, especialmente en El zafarrancho aquel de via Merulana, que lejos de pretender retratar la sociedad italiana de posguerra - a la manera de Pavese en, por ejemplo, Entre mujeres solas (1949) o, en el plano cinematográfico, de De Sica en Ladrón de bicicletas (1948) - presenta un mundo caótico, desordenado, a través de los distintos registros dialectales de Italia durante el fascismo.

2 Se agradecen los aportes del profesor Silvio Cornú en la traducción del fragmento en cuestión.

3 En el pasaje en cuestión tiene lugar el siguiente monólogo de Simon Tanner, el protagonista, mientras contempla el cadáver de Sebastian, el novio poeta de su hermana Hedwig: «La gente está siempre dispuesta a hacerles daño a las aves raras como tú, y a burlarse de sus sufrimientos. Saluda a los queridos y silenciosos muertos debajo de la tierra y no ardas demasiado en las eternas llamas del no ser» (Walser, 2008: 109) («Die Menschen sind immer geneigt, derartigen Käuzen, wie $d u$ einer warst, weh zu tun und ihre Schmerzen zu verlachen. Grüße die lieben, stillen Toten unter der Erde und brenne nicht zu sehr in den ewigen Flammen des Nichtmehrseins»). Inmediatamente, una vez concluido el monólogo de Simon, el narrador en tercera persona continúa realizando algunas consideraciones sobre el episodio en un registro similar al estilo directo con el que se plasmaban los pensamientos del personaje: «Pues, ¿qué era un muerto? Oh, una incitación a la vida. Nada más. Un adorable recuerdo que evoca el pasado y nos impulsa a la vez hacia el futuro incierto y maravilloso» (Walser, 2008: 110). («Was war denn ein Toter? Ei, eine Mahnung ans Leben. Weiter gar nichts. Eine köstliche zurückrufende Erinnerung und zugleich ein Treiben in die ungewisse, schöne Zukunft»). Con lo cual, en este caso el narrador en tercera persona puede pensarse como una extensión del monólogo del personaje. Se trata, en suma, de un modo de mimetización entre narrador y personaje; procedimiento que Walser terminará llevando al extremo en El bandido.

4 Esta novela de Ford Madox Ford constituye otro claro caso de narrador no confiable, justamente por la tendencia a la divagación (a la manera del Tristram Shandy de Sterne) que caracteriza a su narrador. Aunque, a diferencia del Tristram Shandy, en El buen soldado el carácter disperso del narrador tiene mayor peso puesto que las constantes digresiones del narrador entorpecen el relato de la trágica historia que sostiene la trama de la novela.

5 Uno de los motivos es el hecho de que en 1970 Gadda sumó dos capítulos más a la edición original de 1963.

6 El cuento «The Vane Sister» (1959) de Vladimir Nabokov, cuyo final depende enteramente de la comprensión y sagacidad del lector, puede ser mencionado como ejemplo de un narrador no confiable debido a la cualidad despistada de su narrador.

\section{Sobre el autor}

\author{
Licenciado en Letras por la Universidad Nacional del Litoral. Actualmente se encuentra realizando una \\ investigación sobre el narrador no confiable en el marco de su tesis del Doctorado en Humanidades (UNL).
}

